\title{
Breast cancer incidence and case fatality among 4.7 million women in relation to social and ethnic background: a population-based cohort study
}

Omid Beiki ${ }^{1,2^{*}}$, Per Hall ${ }^{3}$, Anders Ekbom ${ }^{4}$ and Tahereh Moradi ${ }^{1}$

\begin{abstract}
Introduction: Incidence of breast cancer is increasing around the world and it is still the leading cause of cancer mortality in low- and middle-income countries. We utilized Swedish nationwide registers to study breast cancer incidence and case fatality to disentangle the effect of socioeconomic position (SEP) and immigration from the trends in native Swedes.
\end{abstract}

Methods: A nation-wide cohort of women in Sweden was followed between 1961 and 2007 and incidence rate ratio (IRR) and hazard ratio (HR) with 95\% confidence intervals (Cls) were estimated using Poisson and Cox proportional regression models, respectively.

Results: Incidence continued to increase; however, it remained lower among immigrants (IRR $=0.88,95 \% \mathrm{Cl}=$ 0.86 to 0.90 ) but not among immigrants' daughters (IRR $=0.97,95 \% \mathrm{Cl}=0.94$ to 1.01 ) compared to native Swedes. Case fatality decreased over the last decades and was similar in native Swedes and immigrants. However, case fatality was significantly 14\% higher if cancer was diagnosed after age 50 and 20\% higher if cancer was diagnosed in the most recent years among immigrants compared with native Swedes. Women with the highest SEP had significantly 20\% to 30\% higher incidence but had 30\% to 40\% lower case fatality compared with women with the lowest SEP irrespective of country of birth. Age at immigration and duration of residence significantly modified the incidence and case fatality.

Conclusions: Disparities found in case fatality among immigrants by age, duration of residence, age at immigration and country of birth emphasize the importance of targeting interventions on women that are not likely to attend screenings or are not likely to adhere to the therapy suggested by physicians. The lower risk of breast cancer among immigrant women calls for more knowledge about how the lifestyle factors in these women differ from those with high risk, so that preventative measures may be implemented.

\section{Introduction}

Breast cancer is the most common tumor among women worldwide. However, there is large geographical variation in its incidence; with the exception for Japan, the incidence ranks highest in high-income countries [1]. More than half of the incident cases in the world occur in Europe and North America [2]. The incidence of breast cancer has been increasing since the 1970s even in countries with a reported low rate, such as Japan, Korea, India and even Africa which lacks accurate

\footnotetext{
* Correspondence: omid.beiki@ki.se

'Division of Epidemiology, Institute of Environmental Medicine, Karolinska Institutet, Box 210, SE-171 77, Stockholm, Sweden

Full list of author information is available at the end of the article
}

population data [2]. A Westernized life-style, including older age at giving birth to a first child and fewer children, are among the explanations for the increasing incidence seen worldwide [3].

Despite the substantial improvement in breast cancer prognosis and survival, it is still the leading cause of cancer mortality in low- and middle-income countries and more than half of the breast cancer mortality is reported from low- and middle-income countries [4].

Migrant studies are classical tools for exploring the importance of environmental, social and genetic factors in the etiology of diseases and has been particularly important for disentangling the etiology of cancer [5]. Migrant studies have also been performed to explore
C Biomed Central 
differences in mortality, if any, among immigrants and the host country. Migration from low- to high-incidence countries, particularly if migration takes place at young ages $[6,7]$, has been shown to influence both incidence and mortality from breast cancer. Differences found in these studies might be explained by differences in biologic and pathologic characteristics of cancer, quality of medical care, such as delays in follow-up after abnormal screening, and disparities in the receipt of cancer treatment.

In this large, nationwide cohort study, we utilized Sweden's established system of demographic and medical population-based registers to explore the impact of country of birth and social position on breast cancer incidence and case fatality among large and growing immigrant populations and their daughters in Sweden and among native Swedes.

\section{Materials and methods \\ Database}

The cohort was built through linkages between Swedish national registers using personal identity numbers (PIN). PIN is a 10-digit number which is maintained by the National Tax Board office for all individuals who have resided longer than one year in Sweden since 1947 [8]. The linkages have been completed by Statistics Sweden and the Centre for Epidemiology at the National Board of Health and Welfare.

For the purpose of this study, we used: 1) The Swedish Cancer Registry, which was founded in 1958 and covers the whole population of Sweden. It is compulsory for every health care provider to report newly detected cancer cases diagnosed at clinical, pathological or other laboratory examinations, as well as cases diagnosed at autopsy to the registry. The overall completeness of the registry is high and close to $100 \%$ [9]; 2) The National Population and Housing Censuses cover demographic, occupational and socioeconomic factors, such as income, occupation and education for the total population of Sweden between 1960 and 1990. This practice ended in 1990 [10] and was substituted by Longitudinal Integration Database for Health Insurance and Labor Market studies (LISA by Swedish acronym). LISA is a yearlyupdated nationwide database consisting of data from 1990 and onwards on all individuals 16 years or older registered as living in Sweden [11]. We obtained individual information on highest level of education from these two registers; 3) the Multi-Generation Register, where we obtained information on reproductive history as well as the links between parents and children. The register consists of all individuals born in 1932 or later who were registered in Sweden sometime after 1961 [12]; 4) The Cause of Death Register, where the information on cause-specific mortality was obtained. The number of non-reported cases in this register is low and previous studies support the use of this register as an appropriate source of breast cancer death in Sweden [13]; and 5) The Swedish Population Register, including the country of birth of the Swedish population [14]. To ensure confidentiality, the PIN was replaced by serial numbers through Statistics Sweden. We have obtained permission to use the databases and registries we used in our study from the Regional Board of The Ethical Committee, Stockholm (Dnr: 2005/726-31 and amendment 2009/587-32).

\section{Classification of country of birth, socio-economic position, and covariates}

We classified foreign-born individuals into six groups by the continents. We further subdivided continents into world regions, as defined by the United Nations Population Division. We report pooled data for countries and regions when we did not have enough power. For detailed information about the final classification, please refer to Tables 1,2,3,4,5 and 6. We classified study participants into three groups: i) women born outside of Sweden, called immigrants, ii) women born in Sweden with at least one parent born outside of Sweden, called immigrants' daughters, and iii) Sweden-born women with both parents born in Sweden, called native Swedes. For persons who had no registration of the parental country of birth, it was assumed that the parents originated from the same country as their child.

Highest attained level of education was used as a surrogate indicator for socio-economic position and categorized into four levels $(<9,10$ to $12,13+$ years, and unknown).

We stratified our analysis by age at exit $(<50$ and $50+$ years), calendar period of follow-up with respect to incidence rate (1961 to 1985,1986 to 1995,1996 to 2000 , and 2001 to 2007) and calendar period of diagnosis with respect to case fatality (1961 to 1985,1986 to 1995,1996 to 2000 , and 2001 to 2007) and geographical region of diagnosis (Gothenburg, Linkoping, Lund-Malmo, Stockholm, Umeå, and Uppsala) where each of the six Swedish national Oncologic Centrum is placed. In an attempt to study the possible influence of lifestyle and environmental exposures, we stratified the immigrants by age at immigration (younger than 15 years, 15 to 34 , and 35 years or older) and duration of residence in Sweden (less than 5 years, 5 to 14,15 to 29 , and 30 years or longer).

\section{Incidence cohort and statistical analysis}

There were 4,749,611 women registered in the Swedish Population Register who were born after 1 January 1930 and lived in Sweden at any time during 1 January 1961 and 31 December 2007. We excluded women with an unknown birthplace $(0.03 \%)$, with a history of breast cancer before the start date of the study $(0.01 \%)$, for 
Table 1 Incidence rate ratio of breast cancer by country of birth, 1961 to 2007

\begin{tabular}{|c|c|c|c|c|c|c|c|}
\hline Birth region & No. & PYRS $\$$ & IRR* $(95 \% \mathrm{CI})$ & Birth region & No. & PYRS $\$$ & IRR* $^{*}(95 \% \mathrm{CI})$ \\
\hline All immigrants & 8,853 & 12,056 & $0.88(0.86$ to 0.90$)$ & Poland & 474 & 582 & $0.79(0.73$ to 0.87$)$ \\
\hline Africa & 131 & 427 & $0.64(0.54$ to 0.76$)$ & Romania & 98 & 112 & 0.89 (0.73 to 1.09$)$ \\
\hline Eastern/Middle & 65 & 269 & $0.55(0.43$ to 0.70$)$ & Soviet Uniont & 151 & 168 & 0.94 (0.80 to 1.10$)$ \\
\hline Eritrea & 14 & 38 & 0.71 (0.42 to 1.19$)$ & Northern & 4,496 & 5,059 & 0.93 (0.90 to 0.96$)$ \\
\hline Ethiopia & 26 & 91 & 0.71 (0.48 to 1.05 ) & Denmark & 460 & 468 & 0.98 (0.90 to 1.08$)$ \\
\hline Other & 25 & 140 & $0.40(0.27$ to 0.59$)$ & Estonia & 136 & 114 & 0.93 (0.78 to 1.10$)$ \\
\hline Northern & 46 & 82 & 0.87 (0.65 to 1.16 ) & Finland & 3,321 & 3,753 & 0.93 (0.90 to 0.97$)$ \\
\hline Egypt & 12 & 15 & 0.97 (0.55 to 1.70$)$ & Iceland & 29 & 46 & 1.18 (0.82 to 1.70$)$ \\
\hline Morocco & 20 & 34 & 0.88 (0.57 to 1.37$)$ & Latvia & 27 & 23 & 1.09 (0.75 to 1.59$)$ \\
\hline Other & 14 & 32 & 0.78 (0.46 to 1.32 ) & Norway & 427 & 528 & 0.84 (0.76 to 0.92$)$ \\
\hline Southern & 6 & 9 & 0.89 (0.40 to 1.98$)$ & UK & 87 & 108 & 0.94 (0.76 to 1.16$)$ \\
\hline South Africa & 6 & 8 & 1.02 (0.46 to 2.26$)$ & Other & 9 & 18 & 0.72 (0.37 to 1.38$)$ \\
\hline Other & 0 & 1 & NA & Southern & 1,077 & 1522 & 0.85 (0.80 to 0.90$)$ \\
\hline \multirow[t]{2}{*}{ Western } & 14 & 67 & $0.49(0.29$ to 0.82$)$ & Bosnia & 250 & 343 & 0.78 (0.69 to 0.89$)$ \\
\hline & & & & Greece & 102 & 161 & 0.84 (0.69 to 1.01$)$ \\
\hline Asia & 961 & 2,392 & $0.73(0.69$ to 0.79$)$ & Italy & 50 & 57 & 1.03 (0.78 to 1.35$)$ \\
\hline Eastern & 69 & 281 & $0.63(0.50$ to 0.80$)$ & Portugal & 30 & 33 & 1.18 (0.82 to 1.68$)$ \\
\hline China & 31 & 85 & $0.58(0.41$ to 0.83$)$ & Spain & 40 & 52 & 0.91 (0.67 to 1.24$)$ \\
\hline Japan & 23 & 30 & 0.80 (0.53 to 1.21$)$ & Yugoslaviat & 604 & 872 & $0.84(0.78$ to 0.91$)$ \\
\hline Korea Rep. & 11 & 152 & $0.53(0.29$ to 0.96$)$ & Other & 1 & 4 & $0.32(0.05$ to 2.29$)$ \\
\hline Other & 4 & 14 & 0.55 (0.20 to 1.46$)$ & Western & 801 & 751 & 0.93 (0.87 to 1.00$)$ \\
\hline South-Central & 310 & 722 & 0.78 (0.69 to 0.87$)$ & Austria & 84 & 76 & 1.07 (0.86 to 1.33$)$ \\
\hline India & 27 & 146 & 0.74 (0.50 to 1.07 ) & France & 33 & 41 & 0.94 (0.67 to 1.32$)$ \\
\hline Iran & 252 & 412 & 0.86 (0.76 to 0.98$)$ & Germany & 612 & 562 & 0.91 (0.84 to 0.98$)$ \\
\hline Sri Lanka & 14 & 70 & 0.63 (0.37 to 1.07 ) & Netherlands & 39 & 42 & 0.97 (0.71 to 1.32$)$ \\
\hline Other & 17 & 94 & $0.34(0.21$ to 0.55$)$ & Switzerland & 25 & 20 & $1.29(0.87$ to 1.91$)$ \\
\hline South-Eastern & 109 & 376 & $0.53(0.44$ to 0.64$)$ & Other & 8 & 10 & 0.89 (0.45 to 1.78$)$ \\
\hline Philippines & 34 & 72 & 0.74 (0.53 to 1.04 ) & & & & \\
\hline Thailand & 38 & 159 & $0.47(0.34$ to 0.65$)$ & Latin America & 245 & 588 & 0.65 (0.57 to 0.74$)$ \\
\hline Viet Nam & 23 & 106 & $0.40(0.27$ to 0.61$)$ & Argentina & 25 & 28 & 1.15 (0.78 to 1.70$)$ \\
\hline Other & 14 & 38 & 0.64 (0.38 to 1.08 ) & Bolivia & 10 & 23 & $0.72(0.39$ to 1.33$)$ \\
\hline Western & 473 & 1014 & $0.78(0.71$ to 0.85$)$ & Brazil & 18 & 38 & 0.78 (0.49 to 1.24$)$ \\
\hline Iraq & 198 & 324 & 1.01 (0.87 to 1.17 ) & Chile & 105 & 286 & 0.52 (0.43 to 0.63$)$ \\
\hline Lebanon & 64 & 166 & 0.84 (0.66 to 1.08 ) & Peru & 21 & 38 & 0.78 (0.51 to 1.20$)$ \\
\hline Syria & 82 & 130 & 0.95 (0.76 to 1.18 ) & Uruguay & 25 & 28 & 1.12 (0.75 to 1.65$)$ \\
\hline Turkey & 106 & 334 & $0.48(0.40$ to 0.58$)$ & Other & 41 & 147 & 0.61 (0.45 to 0.83$)$ \\
\hline \multirow[t]{2}{*}{ Other } & 23 & 60 & 0.64 (0.43 to 0.97$)$ & & & & \\
\hline & & & & North America & 84 & 112 & 0.90 (0.73 to 1.12$)$ \\
\hline Europe & 7,426 & 8,518 & 0.91 (0.89 to 0.93$)$ & Canada & 9 & 16 & 0.71 (0.37 to 1.36$)$ \\
\hline Eastern & 1,052 & 1,186 & 0.87 (0.82 to 0.92$)$ & USA & 75 & 96 & 0.94 (0.75 to 1.17$)$ \\
\hline Bulgaria & 26 & 33 & 0.91 (0.62 to 1.34 ) & & & & \\
\hline Czechoslovakia & 92 & 108 & 0.79 (0.65 to 0.97$)$ & Oceania & 6 & 19 & $0.61(0.27$ to 1.36$)$ \\
\hline Hungary & 211 & 181 & 1.07 (0.93 to 1.22$)$ & & & & \\
\hline
\end{tabular}

* IRRs are adjusted for age at follow-up and calendar period of follow-up, education and place of residence at diagnosis. Native Swedish women with both parents born in Sweden were the reference group. \$ PYRS = person-years at risk divided by 1000. † Czechoslovakia includes Czech Republic and Slovakia. Soviet Union includes Belarus, Moldova, Russian Federation and Ukraine. Yugoslavia includes Croatia, Macedonia, Serbia, Slovenia and Montenegro.

whom we found a death date $(0.01 \%)$ or an emigration date $(2.5 \%)$ before entry into the cohort (January 1961, date of birth or first immigration date or their first appearance in census, whichever occurred last).
The final cohort was followed from 1 January 1961, date of birth or first immigration date for immigrants, whichever occurred last, until they exited from the cohort, which was the date of diagnosis of breast cancer 
Table 2 Incidence rate ratio (IRR) of breast cancer among immigrants' daughters in Sweden, 1961 to 2007

\begin{tabular}{|c|c|c|c|c|}
\hline & \multirow[t]{2}{*}{ Cases } & \multirow[t]{2}{*}{ PYRS $\$$} & \multicolumn{2}{|c|}{$\operatorname{IRR}^{*}(95 \% \mathrm{Cl})$} \\
\hline & & & Vs. native Swedes & Vs. mothers \\
\hline All immigrants' daughters & 2,808 & 11,457 & 0.97 (0.94 to 1.01) & 1.08 (1.03 to 1.12$)$ \\
\hline Africa & 7 & 340 & $0.60(0.29$ to 1.25$)$ & 0.60 (0.27 to 1.30$)$ \\
\hline Northern & 4 & 136 & 1.00 (0.37 to 2.65$)$ & 1.46 (0.50 to 4.28$)$ \\
\hline Africa except Northern & 3 & 206 & 0.39 (0.13 to 1.21$)$ & 0.39 (0.12 to 1.27$)$ \\
\hline Asia & 31 & 1,039 & 1.10 (0.78 to 1.57$)$ & 1.18 (0.82 to 1.71$)$ \\
\hline Eastern & 15 & 82 & 1.60 (0.96 to 2.65$)$ & 2.09 (1.17 to 3.71$)$ \\
\hline South-Central & 7 & 245 & 0.84 (0.40 to 1.76$)$ & $0.88(0.41$ to 1.90$)$ \\
\hline South-Eastern & 3 & 133 & $1.11(0.36$ to 3.44$)$ & $1.71(0.53$ to 5.55$)$ \\
\hline Western & 6 & 592 & 0.78 (0.35 to 1.74$)$ & 0.53 (0.23 to 1.23$)$ \\
\hline Europe & 2,538 & 9,590 & 0.97 (0.93 to 1.01$)$ & 1.04 (0.99 to 1.09$)$ \\
\hline Eastern & 227 & 901 & 0.97 (0.85 to 1.10$)$ & 1.09 (0.94 to 1.27$)$ \\
\hline Czechoslovakia $^{\dagger}$ & 28 & 121 & 0.91 (0.63 to 1.31$)$ & 1.15 (0.70 to 1.87$)$ \\
\hline Hungary & 36 & 219 & 0.88 (0.63 to 1.22$)$ & 1.00 (0.65 to 1.53$)$ \\
\hline Poland & 66 & 349 & 0.88 (0.69 to 1.12 ) & 1.09 (0.84 to 1.42$)$ \\
\hline Soviet Union ${ }^{\dagger}$ & 96 & 171 & 1.15 (0.94 to 1.40$)$ & 1.14 (0.87 to 1.49$)$ \\
\hline Other & 10 & 60 & 1.22 (0.66 to 2.28$)$ & 1.20 (0.62 to 2.33$)$ \\
\hline Northern & 1,902 & 6,628 & 0.96 (0.92 to 1.01$)$ & 1.01 (0.95 to 1.08 ) \\
\hline Denmark & 332 & 963 & $0.99(0.89$ to 1.11$)$ & 1.01 (0.86 to 1.19$)$ \\
\hline Estonia & 144 & 329 & 0.97 (0.82 to 1.14$)$ & 1.34 (0.96 to 1.89$)$ \\
\hline Finland & 830 & 3,920 & 0.94 (0.88 to 1.01$)$ & 0.98 (0.90 to 1.07$)$ \\
\hline Latvia & 22 & 53 & 0.91 (0.60 to 1.39 ) & 0.96 (0.47 to 1.93$)$ \\
\hline Norway & 556 & 1,230 & 0.96 (0.88 to 1.04$)$ & 1.14 (0.99 to 1.31$)$ \\
\hline UK & 36 & 184 & 1.08 (0.78 to 1.50$)$ & 1.12 (0.75 to 1.68$)$ \\
\hline Other & 8 & 43 & 1.13 (0.57 to 2.27$)$ & 1.01 (0.46 to 2.21$)$ \\
\hline Southern & 54 & 989 & 0.85 (0.65 to 1.11$)$ & 0.87 (0.65 to 1.16$)$ \\
\hline Italy & 23 & 137 & 0.99 (0.66 to 1.48$)$ & 0.95 (0.51 to 1.78$)$ \\
\hline Yugoslavia $^{\dagger}$ & 15 & 545 & 0.62 (0.37 to 1.02 ) & 0.69 (0.40 to 1.19$)$ \\
\hline Other & 16 & 331 & 0.95 (0.58 to 1.56$)$ & 0.86 (0.50 to 1.45$)$ \\
\hline Western & 418 & 1,338 & 1.01 (0.92 to 1.11$)$ & 1.12 (0.97 to 1.30$)$ \\
\hline Austria & 48 & 166 & 1.01 (0.76 to 1.34$)$ & 0.82 (0.53 to 1.24$)$ \\
\hline France & 21 & 75 & 1.13 (0.74 to 1.74$)$ & 1.37 (0.75 to 2.52 ) \\
\hline Germany & 326 & 970 & 1.04 (0.93 to 1.16$)$ & 1.26 (1.07 to 1.50$)$ \\
\hline Netherlands & 20 & 84 & 0.95 (0.62 to 1.48$)$ & 0.80 (0.43 to 1.47$)$ \\
\hline Other & 12 & 60 & 0.70 (0.40 to 1.23$)$ & $0.48(0.23$ to 0.98$)$ \\
\hline Latin America & 12 & 272 & 1.22 (0.69 to 2.15$)$ & 2.00 (1.11 to 3.60$)$ \\
\hline North America & 228 & 369 & 1.04 (0.91 to 1.19$)$ & 1.03 (0.79 to 1.35$)$ \\
\hline Canada & 11 & 32 & 0.92 (0.51 to 1.67$)$ & 1.23 (0.47 to 3.19 ) \\
\hline USA & 217 & 336 & 1.05 (0.92 to 1.20$)$ & 0.99 (0.75 to 1.31$)$ \\
\hline Oceania & 4 & 16 & 3.26 (1.22 to 8.69$)$ & 5.34 (1.16 to 24.60$)$ \\
\hline
\end{tabular}

* All IRRs are adjusted for age at follow-up, calendar period of follow-up, years of education and place of residence at diagnosis. Native Swedish women with both parents born in Sweden were the reference group. ${ }^{\$}$ PYRS $=$ person-years at risk divided by $1,000 .{ }^{\dagger}$ Czechoslovakia includes Czech Republic and Slovakia. Soviet Union includes Belarus, Moldova, Russian Federation and Ukraine. Yugoslavia includes Croatia, Macedonia, Serbia, Slovenia and Montenegro.

(ICD-7 code: 170 Malignant Neoplasm of Breast), first emigration date, death or end of follow-up (31 December 2007), whichever came first.

We calculated the incidence rate ratios (IRRs) with 95\% confidence intervals (CIs) using Poisson regression models. All analyses were adjusted for age at follow-up ( 0 to 14,15 to 29,30 to 34,35 to 39,40 to 44,45 to 49 , 50 to 54,55 to 59,60 to 64,65 to 69 and $70+$ ) and calendar period of follow-up (1961 to $1965, \ldots \ldots . ., 2001$ to 2005, 2006 to 2007.

Case fatality cohort and statistical analysis

The outcomes of interests were death due to any cause and death due to breast cancer as the underlying cause of death. In all, 76,152 women were diagnosed with primary invasive breast cancer. To avoid inclusion of cases 
Table 3 Incidence rate ratio (IRR) in Sweden by education, calendar year and area of diagnosis

\begin{tabular}{|c|c|c|c|c|c|c|c|c|c|}
\hline & \multicolumn{3}{|c|}{ Immigrants } & \multicolumn{3}{|c|}{ Immigrants' daughters } & \multicolumn{3}{|c|}{ Native Swedes } \\
\hline & Cases & PYRS $\$$ & $\operatorname{IRR}^{*}(95 \% \mathrm{CI})$ & Cases & PYRS $\$$ & $\operatorname{IRR}^{*}(95 \% \mathrm{CI})$ & Cases & PYRS $^{\$}$ & $\mathrm{IRR}^{*}(95 \% \mathrm{Cl})$ \\
\hline \multicolumn{10}{|l|}{ Years of education } \\
\hline $13+$ & 2,142 & 2,661 & $1.28(1.21$ to 1.36$)$ & 1,029 & 3,010 & 1.18 (1.06 to 1.32$)$ & 17,963 & 3,0772 & $1.18(1.16$ to 1.21$)$ \\
\hline 10 to 12 & 3,365 & 4,572 & 1.14 (1.08 to 1.20$)$ & 1,292 & 4,521 & 1.07 (0.96 to 1.19$)$ & 26,595 & 4,6316 & 1.05 (1.03 to 1.07$)$ \\
\hline 0 to 9 & 2,866 & 3,529 & Reference & 478 & 1,641 & Reference & 19,644 & 2,3095 & Reference \\
\hline Unknown & 480 & 1,296 & $1.02(0.93$ to 1.13$)$ & 9 & 2,286 & 0.99 (0.50 to 1.89$)$ & 289 & 8,864 & 1.41 (1.26 to 1.58$)$ \\
\hline \multicolumn{10}{|c|}{ Calendar period of follow-up } \\
\hline 1961 to 1985 & 1,069 & 3,738 & $0.83(0.75$ to 0.91$)$ & 145 & 3,992 & $0.82(0.66$ to 1.01$)$ & 8,321 & 48,239 & $0.75(0.73$ to 0.78$)$ \\
\hline 1986 to 1995 & 2,123 & 2,991 & 0.87 (0.81 to 0.92$)$ & 565 & 2,826 & 0.92 (0.81 to 1.03$)$ & 16,687 & 25,836 & 0.87 (0.85 to 0.89$)$ \\
\hline 1996 to 2000 & 1,848 & 2,003 & 0.89 (0.84 to 0.95$)$ & 674 & 1,769 & $1.05(0.96$ to 1.16$)$ & 14,046 & 14,169 & 0.95 (0.93 to 0.97$)$ \\
\hline 2001 to 2007 & 3,813 & 3,328 & Reference & 1,424 & 2,871 & Reference & 25,437 & 20,803 & Reference \\
\hline \multicolumn{10}{|c|}{ Area of residence at diagnosis } \\
\hline Gothenburg & 1,641 & 2,391 & 0.93 (0.87 to 0.98$)$ & 543 & 2,313 & 0.89 (0.80 to 1.00$)$ & 11,548 & 21,632 & $0.83(0.81$ to 0.85$)$ \\
\hline Linkoping & 687 & 950 & 1.00 (0.92 to 1.09$)$ & 201 & 884 & 0.89 (0.76 to 1.04$)$ & 7,341 & 12,762 & $0.87(0.84$ to 0.89$)$ \\
\hline Lund-Malmo & 1,569 & 1,993 & $1.05(0.98$ to 1.11$)$ & 437 & 1,730 & 0.99 (0.88 to 1.11$)$ & 12,003 & 18,074 & 0.99 (0.97 to 1.02$)$ \\
\hline Stockholm & 2,906 & 3,898 & Reference & 839 & 3,497 & Reference & 12,992 & 20,870 & Reference \\
\hline Umea & 460 & 648 & 0.94 (0.85 to 1.03 ) & 250 & 827 & $0.79(0.69$ to 0.91$)$ & 6,653 & 12,301 & 0.80 (0.77 to 0.82$)$ \\
\hline Uppsala & 1,590 & 2,131 & 0.97 (0.91 to 1.03 ) & 538 & 2,123 & 0.90 (0.81 to 1.00$)$ & 13,954 & 23,171 & 0.89 (0.87 to 0.91$)$ \\
\hline
\end{tabular}

* All IRRs are adjusted for age at follow-up and calendar period of follow-up and the other two variables shown. ${ }^{5}$ PYRS $=$ person-years at risk divided by 1,000 .

detected by autopsy but not registered as such, we excluded $259(0.34 \%)$ women who died within one month of diagnosis.

Breast cancer patients were followed from date of diagnosis until date of death, first emigration date, or end of follow-up (31 December 2007), whichever came first. In breast cancer-specific case fatality analysis, the patient's follow-up was censored if either death for other reasons or emigration took place. Hazard ratios (HRs) with 95\% confidence intervals (CIs) for breast cancer patients were calculated using stratified Cox proportional hazards regression model. Point estimates and 95\% CIs were produced using the maximum partial likelihood for the effect estimates. The validity of the

Table 4 Incidence rate ratio (IRR) among immigrants by age at immigration and duration of residence, 1961-2007

\begin{tabular}{lcc}
\hline & \multicolumn{2}{c}{ Incidence of breast cancer } \\
\cline { 2 - 3 } & Cancer & IRR $^{*}(\mathbf{9 5 \%} \mathrm{Cl})$ \\
\hline Age at immigration & & \\
0 to 14 & 835 & $\mathbf{0 . 8 5}(\mathbf{0 . 7 7}$ to $\mathbf{0 . 9 3})$ \\
15 to 34 & 5,276 & $1.02(0.96$ to 1.08$)$ \\
$35+$ & 1,702 & Reference \\
Duration of residence & & \\
0 to 4 & 660 & $\mathbf{0 . 8 8}(\mathbf{0 . 7 9}$ to $\mathbf{0 . 9 8})$ \\
5 to 14 & 1,523 & $\mathbf{0 . 9 1}(\mathbf{0 . 8 4}$ to $\mathbf{0 . 9 8})$ \\
15 to 29 & 2,557 & $\mathbf{0 . 9 2}(\mathbf{0 . 8 7}$ to $\mathbf{0 . 9 8})$ \\
$30+$ & 3,073 & Reference \\
\hline
\end{tabular}

* All IRRs are adjusted for age at follow-up, calendar period of follow-up and region of origin. proportional hazards assumption was evaluated using a martingale residual based graphical and numerical approach.

\section{Results}

Incidence

Our cohort comprised 4,553,484 women, of which 760,214 (16.7\%) were immigrants, 495,917 (10.9\%) were immigrants' daughters and 3,297,353 (72.4\%) were native Swedish women. We observed 76,152 cases of breast cancer during 133 million person-years of follow-up in our cohort. Immigrants $(52.4, \mathrm{SD} \pm 10.2)$ and native Swedish women (53.2, SD \pm 10.0 ) had a similar age at diagnosis. Age at diagnosis among immigrants' daughters was on average $48.6(\mathrm{SD} \pm 9.4)$. Mean age at immigration was $22.6(\mathrm{SD} \pm 13.4$ ) years ranking from the highest among immigrants from Bosnia (29.1, SD \pm 16.4) and lowest among immigrants from the Republic of Korea (6.3, SD \pm 11.2 ). Mean duration of residence was $15.9(\mathrm{SD} \pm 4.8)$ years, ranking from the highest among immigrants from Austria (28.3, SD \pm 21.1$)$ and the lowest among immigrants from China (6.9, SD \pm 7.1).

Overall, immigrants had lower incidence (IRR $=0.88$, $95 \% \mathrm{CI}=0.86$ to 0.90 ) of breast cancer while their daughters had a similar incidence (IRR $=0.97,95 \% \mathrm{CI}=$ 0.94 to 1.01 ) compared with native Swedes (Tables 1 and 2).

Except for Northern America and Oceania, immigrants born in all other continents were at significantly lower incidence of breast cancer compared to native 
Table 5 Hazard ratio (HR) of case fatality of breast cancer by education, calendar year and area of diagnosis

\begin{tabular}{|c|c|c|c|c|}
\hline & \multicolumn{2}{|c|}{ Immigrants } & \multicolumn{2}{|c|}{ Immigrants' daughters } \\
\hline & Death & $\mathrm{HR}^{*}(95 \% \mathrm{Cl})$ & Death & $\mathrm{HR}^{*}(95 \% \mathrm{Cl})$ \\
\hline \multicolumn{5}{|l|}{ Years of education } \\
\hline $13+$ & 285 & 1.01 (0.88 to 1.17$)$ & 144 & $0.98(0.80$ to 1.20$)$ \\
\hline 10 to 12 & 542 & 0.99 (0.90 to 1.09$)$ & 202 & 0.98 (0.83 to 1.15$)$ \\
\hline 0 to 9 & 621 & 1.03 (0.94 to 1.13$)$ & 94 & 0.85 (0.67 to 1.09$)$ \\
\hline Unknown & 130 & 0.92 (0.59 to 1.44$)$ & 6 & $0.65(0.17$ to 2.51$)$ \\
\hline \multicolumn{5}{|c|}{ Calendar period of diagnosis } \\
\hline 1961 to 1985 & 444 & 0.98 (0.87 to 1.10$)$ & 49 & 0.84 (0.59 to 1.19$)$ \\
\hline 1986 to 1995 & 615 & 0.94 (0.86 to 1.04$)$ & 192 & $0.96(0.82$ to 1.13$)$ \\
\hline 1996 to 2000 & 282 & 1.10 (0.95 to 1.27$)$ & 129 & 0.90 (0.73 to 1.10$)$ \\
\hline 2001 to 2007 & 237 & 1.20 (1.01 to 1.43$)$ & 76 & 1.10 (0.83 to 1.45$)$ \\
\hline \multicolumn{5}{|l|}{ Age at diagnosis } \\
\hline 0 to 50 & 132 & 0.92 (0.85 to 1.00$)$ & 82 & 0.94 (0.83 to 1.08$)$ \\
\hline $50+$ & 551 & 1.14 (1.04 to 1.25$)$ & 112 & $0.96(0.78$ to 1.18$)$ \\
\hline \multicolumn{5}{|c|}{ Area of residence at diagnosis } \\
\hline Gothenburg & 314 & 1.03 (0.90 to 1.18$)$ & 88 & $1.16(0.91$ to 1.48$)$ \\
\hline Linkoping & 132 & 1.02 (0.83 to 1.26$)$ & 22 & $0.78(0.47$ to 1.31$)$ \\
\hline Lund-Malmo & 274 & 1.09 (0.94 to 1.26$)$ & 86 & 0.86 (0.66 to 1.11$)$ \\
\hline Stockholm & 476 & 0.97 (0.87 to 1.09) & 124 & 0.88 (0.72 to 1.09$)$ \\
\hline Umea & 103 & 0.96 (0.75 to 1.23$)$ & 44 & 1.07 (0.73 to 1.57$)$ \\
\hline Uppsala & 279 & 0.98 (0.85 to 1.13$)$ & 82 & 0.95 (0.74 to 1.22$)$ \\
\hline
\end{tabular}

* All HRs are adjusted for age at follow-up and calendar period of diagnosis. HRs are also mutually adjusted for years of education and place of residence at diagnosis if applicable. Native Swedish women defined as women with both parents born in Sweden.

Swedes, with women born in Africa having the lowest incidence (IRR $=0.64 ; 95 \%$ CI 0.54 to 0.76 ) followed by immigrants from Latin America (IRR $=0.65 ; 95 \% \mathrm{CI}$ 0.57 to 0.74 ) (Table 1). Within the African continent, women born in eastern, middle and western regions had statistically, significantly half the incidence of native women. Immigrants from all regions in Asia had statistically significantly 20 to $50 \%$ lower incidence compared with native Swedes. Among immigrant women born in this part of world, women born in Thailand, Vietnam and Turkey had the lowest statistically significant incidence compared with native Swedes. Within Europe, there was significantly lower incidence (10 to $15 \%$ ) for women born in eastern, northern and southern regions. The incidence was significantly lower for women born in the former Czechoslovakia (IRR $=0.79 ; 95 \%$ CI 0.65 to 0.97 ), Poland (IRR $=0.79 ; 95 \%$ CI 0.73 to 0.87 ), Finland $(\mathrm{IRR}=0.93 ; 95 \% \mathrm{CI} 0.90$ to 0.97$)$, Norway $(\mathrm{IRR}=$ 0.84; $95 \%$ CI 0.76 to 0.92 ), Bosnia (IRR $=0.78 ; 95 \%$ CI 0.69 to 0.89 ), Germany (IRR $=0.91 ; 95 \%$ CI 0.84 to 0.98), and former Yugoslavia (IRR $=0.84 ; 95 \%$ CI 0.78 to 0.91). Within Latin America, women born in Chile had statistically, significantly $50 \%$ lower incidence compared with native Swedes. Women born in all other studied countries had similar incidence of breast cancer compared with Native Swedes (Table 1).

As shown in Table 2 a convergence toward the incidence of native Swedes was observed among immigrants' daughters. Immigrants' daughters from all continents had similar incidence of breast cancer compared with native Swedes, except for those with either one or both parents born in Oceania that showed a significantly higher incidence (IRR $=3.26,95 \% \mathrm{CI}=1.22$ to 8.69). Immigrants' daughters, with either one or both parents born in Eastern Asia (IRR $=2.09,95 \% \mathrm{CI}=1.17$ to 3.71 ), Latin America ( $\mathrm{IRR}=2.00,95 \% \mathrm{CI}=1.11$ to 3.60 ), and Oceania (IRR $=5.34,95 \% \mathrm{CI}=1.16$ to 24.60 ), had a significantly higher incidence of breast cancer compared with their mothers. At the country level, immigrants' daughters with parents born in Germany $(\mathrm{IRR}=1.26,95 \% \mathrm{CI}=1.07$ to 1.50$)$ had significantly higher incidence of breast cancer compared with their mothers. However, lack of statistical power hindered any definitive conclusion because of wide confidence intervals at the country level.

Irrespective of background, women with the highest educational level had significantly higher incidence of breast cancer compared to those with lower education (Table 3). The incidence was $20 \%$ to $30 \%$ higher among women with the highest versus lowest educational level.

The incidence rate of breast cancer increased to a maximum at age 65 years and then dropped among both immigrants and Sweden-born women. The differences in rates between immigrants and Sweden-born women increased by increasing age at diagnosis (Figure 1). 
Table 6 Hazard ratio (HR) in Sweden by country of birth, 1961 to 2007

\begin{tabular}{|c|c|c|c|c|c|}
\hline Birth region & Death & $\mathrm{HR}^{*}(95 \% \mathrm{Cl})$ & Birth region & Death & $\mathrm{HR}^{*}(95 \% \mathrm{Cl})$ \\
\hline \multirow[t]{2}{*}{ All immigrants } & 1578 & 1.01 (0.95 to 1.07 ) & Other & 4 & 3.25 (1.06 to 9.95$)$ \\
\hline & & & Northern & 840 & 1.02 (0.94 to 1.11$)$ \\
\hline Africa & 27 & 1.10 (0.67 to 1.82 ) & Denmark & 90 & 1.13 (0.90 to 1.43$)$ \\
\hline Eastern/Middle & 17 & 0.81 (0.43 to 1.52 ) & Estonia & 27 & 0.70 (0.45 to 1.11$)$ \\
\hline Ethiopia & 8 & 0.97 (0.37 to 2.52 ) & Finland & 612 & 1.04 (0.95 to 1.14$)$ \\
\hline Other & 9 & 0.74 (0.32 to 1.70$)$ & Iceland & 3 & 2.49 (0.67 to 9.29$)$ \\
\hline Northern & 7 & $2.81(1.13$ to 6.96$)$ & Latvia & 6 & 0.61 (0.24 to 1.55$)$ \\
\hline Southern & 2 & 0.48 (0.05 to 4.23$)$ & Norway & 90 & $0.96(0.76$ to 1.21$)$ \\
\hline \multirow[t]{2}{*}{ Western } & 1 & N/A & UK & 12 & 0.71 (0.35 to 1.44$)$ \\
\hline & & & Southern & 192 & 0.95 (0.80 to 1.11$)$ \\
\hline Asia & 120 & 0.91 (0.72 to 1.14 ) & Bosnia & 36 & 1.40 (0.91 to 2.13$)$ \\
\hline Eastern & 7 & 0.73 (0.31 to 1.74$)$ & Greece & 24 & 0.90 (0.57 to 1.41$)$ \\
\hline South-Central & 40 & 0.93 (0.63 to 1.35$)$ & Italy & 5 & 0.95 (0.38 to 2.34) \\
\hline India & 5 & 0.54 (0.19 to 1.52$)$ & Portugal & 8 & 0.50 (0.21 to 1.16$)$ \\
\hline Iran & 31 & 0.97 (0.63 to 1.51$)$ & Spain & 5 & $0.59(0.21$ to 1.67$)$ \\
\hline Other & 4 & 1.57 (0.54 to 4.53$)$ & Yugoslavia $^{+}$ & 114 & $0.95(0.77$ to 1.17$)$ \\
\hline South-Eastern & 14 & 0.98 (0.49 to 1.98 ) & Western & 175 & $1.02(0.86$ to 1.21$)$ \\
\hline Thailand & 5 & 0.30 (0.07 to 1.29$)$ & Austria & 16 & 1.43 (0.82 to 2.47$)$ \\
\hline Other & 9 & 2.02 (0.90 to 4.53$)$ & France & 7 & 1.00 (0.39 to 2.57$)$ \\
\hline Western & 59 & 0.91 (0.65 to 1.28 ) & Germany & 139 & $1.00(0.83$ to 1.21$)$ \\
\hline Iraq & 19 & 0.76 (0.43 to 1.34$)$ & Netherlands & 9 & 1.21 (0.56 to 2.62) \\
\hline Lebanon & 4 & 0.76 (0.23 to 2.52$)$ & Other & 4 & 0.59 (0.21 to 1.69$)$ \\
\hline Syria & 13 & 0.93 (0.38 to 2.24 ) & & & \\
\hline Turkey & 16 & 1.05 (0.56 to 1.97$)$ & Latin America & 29 & 1.06 (0.67 to 1.66$)$ \\
\hline \multirow[t]{2}{*}{ Other } & 7 & 1.64 (0.57 to 4.77$)$ & Chile & 14 & 1.45 (0.81 to 2.61$)$ \\
\hline & & & Uruguay & 4 & 0.90 (0.19 to 4.38$)$ \\
\hline Europe & 1,388 & 1.01 (0.95 to 1.08$)$ & Other & 11 & 0.72 (0.33 to 1.56$)$ \\
\hline Eastern & 181 & 1.05 (0.88 to 1.24$)$ & & & \\
\hline Czechoslovakia $^{\dagger}$ & 18 & 1.07 (0.62 to 1.85$)$ & North America & 13 & 1.03 (0.49 to 2.16) \\
\hline Hungary & 36 & 0.92 (0.63 to 1.34$)$ & Canada & 2 & 0.71 (0.15 to 3.30$)$ \\
\hline Poland & 89 & $1.26(0.98$ to 1.61$)$ & USA & 11 & 1.18 (0.50 to 2.77$)$ \\
\hline Romania & 16 & 0.71 (0.41 to 1.24 ) & & & \\
\hline Soviet Union ${ }^{\dagger}$ & 18 & 0.81 (0.47 to 1.39 ) & Oceania & 1 & $0.45(0.06$ to 3.36$)$ \\
\hline
\end{tabular}

* HRs are adjusted for age at follow-up and calendar period of diagnosis, education and place of residence at diagnosis. Native Swedish women with both parents born in Sweden were the reference group. ${ }^{\dagger}$ Czechoslovakia includes Czech Republic and Slovakia. Soviet Union includes Belarus, Moldova, Russian Federation and Ukraine. Yugoslavia includes Croatia, Macedonia, Serbia, Slovenia and Montenegro.

Age-specific incidence rates stratified by age at breast cancer diagnosis before and after age 50 are presented in Figure 2. While rates increased by increasing calendar period of follow-up, higher differences of incidence rates between immigrants and Sweden-born women were found in most recent years.

To find whether calendar period of follow-up has any effect on the incidence of breast cancer, we divided our results into four categories of calendar period follow-up. The incidence increased slightly with increasing year of follow-up in that incidence was $20 \%$ higher during most recent years; 2001 to 2007, compared with incidence during 1961 to 1985 . When we stratified results by place of residence at diagnosis, we found those who were residing in Stockholm at diagnosis had a higher incidence of breast cancer compared with those from other areas in Sweden. However, results were statistically significant only among native Swedes (Table 3).

Age at immigration and duration of residence significantly altered the incidence of breast cancer (Table 4). When stratifying the results by age at immigration we found a statistically significant decrease in the incidence by increasing age at immigration among all immigrants as one group (Table 4). This increase was more pronounced among immigrants from low-risk countries in Africa, Asia and Eastern Europe (results not shown). When stratifying by duration of residence, however, we found an overall 10\% lower incidence among immigrants who stayed less than 30 years compared with those who stayed longer in Sweden (Table 4). 


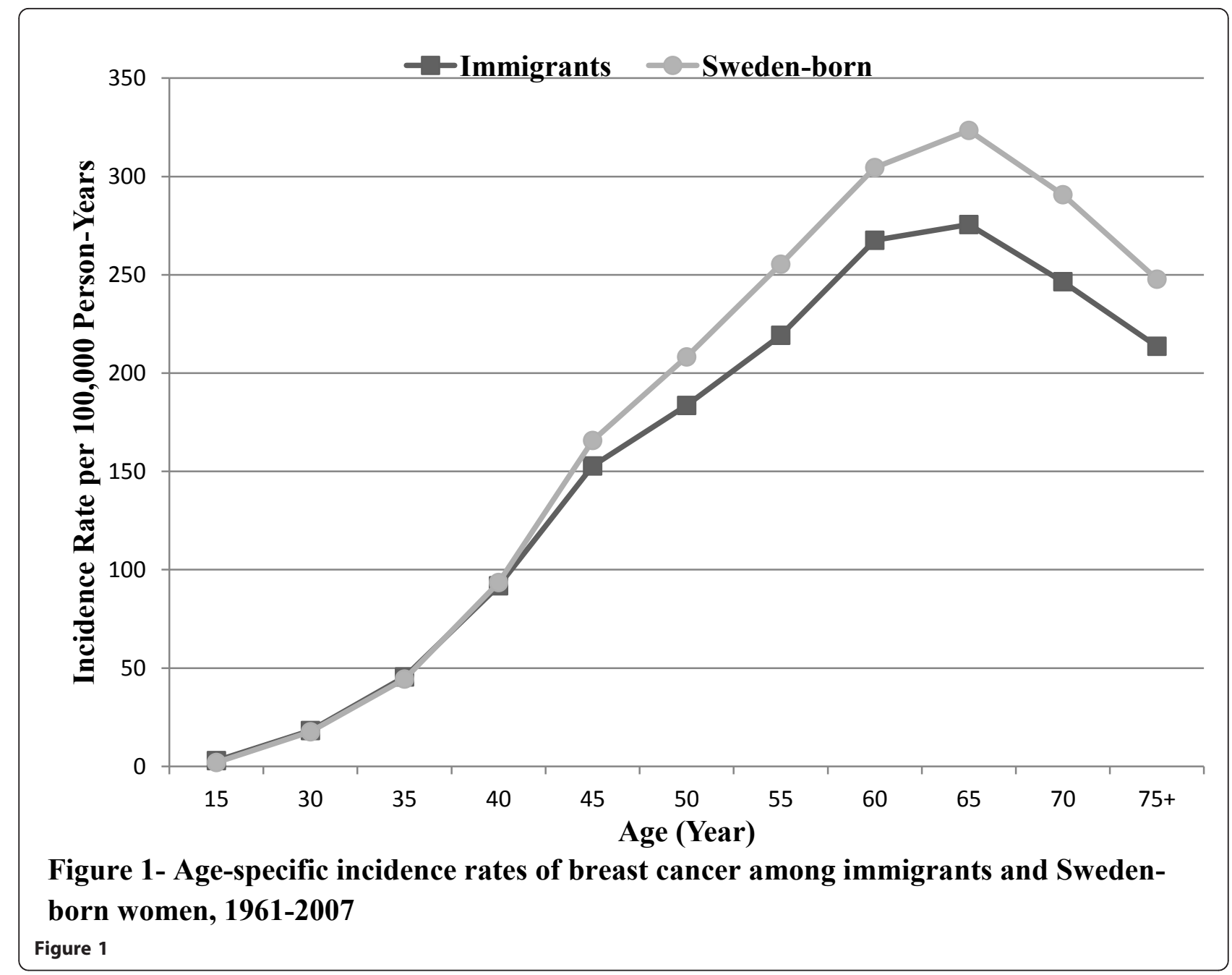

\section{Case fatality}

The final cohort included 75,893 women with breast cancer, of which 8,818 (11.6\%) were immigrants, 2,800 (3.7\%) were immigrant's daughters and 64,275 (84.7\%) were native Swedes.

We observed a total of 14,024 deaths due to breast cancer among 75,893 women with breast cancer; 1,578 death in immigrants, 446 in immigrants' daughters and 12,000 in native women. Women with more education had a better survival compared to women with less education (data not shown in table), irrespective of country of birth. Women with the lowest educational level had around 30\% statistically, significantly higher risk of dying from breast cancer compared with women with the highest level of education (data not shown in table).

We found improving survival over calendar years among native Swedes and immigrants' daughters (Table $5)$. However, immigrants whose cancer was diagnosed in more recent years (2001 to 2007) had a significantly higher risk $(\mathrm{HR}=1.20,95 \% \mathrm{CI}=1.01$ to 1.43$)$ of dying from breast cancer compared with native Swedes, while those with cancer diagnosed in earlier years (1960 to 2000) had a similar risk compared with native Swedes (Table 5).

We further observed an increasing risk of dying due to breast cancer by decreasing age at diagnosis, irrespective of birth country. The risk was $25 \%$ higher if breast cancer was diagnosed at an age younger than $50(\mathrm{HR}=$ $1.24,95 \% \mathrm{CI}=1.18$ to 1.29$)$ than that if cancer was diagnosed at age 50 or older (data not shown in table). In addition, immigrants whose cancer was diagnosed after age 50 had a significantly higher risk $(\mathrm{HR}=1.14$, $95 \% \mathrm{CI}=1.04$ to 1.25 ) of dying from breast cancer, while those with cancer diagnosed before age 50 had a lower risk ( $\mathrm{HR}=0.92,95 \% \mathrm{CI}=0.85$ to 1.00$)$ compared with natives (Table 5).

Compared with Stockholm, all regions had similar case fatality except for Umeå, where the case fatality was higher (Table 5). 


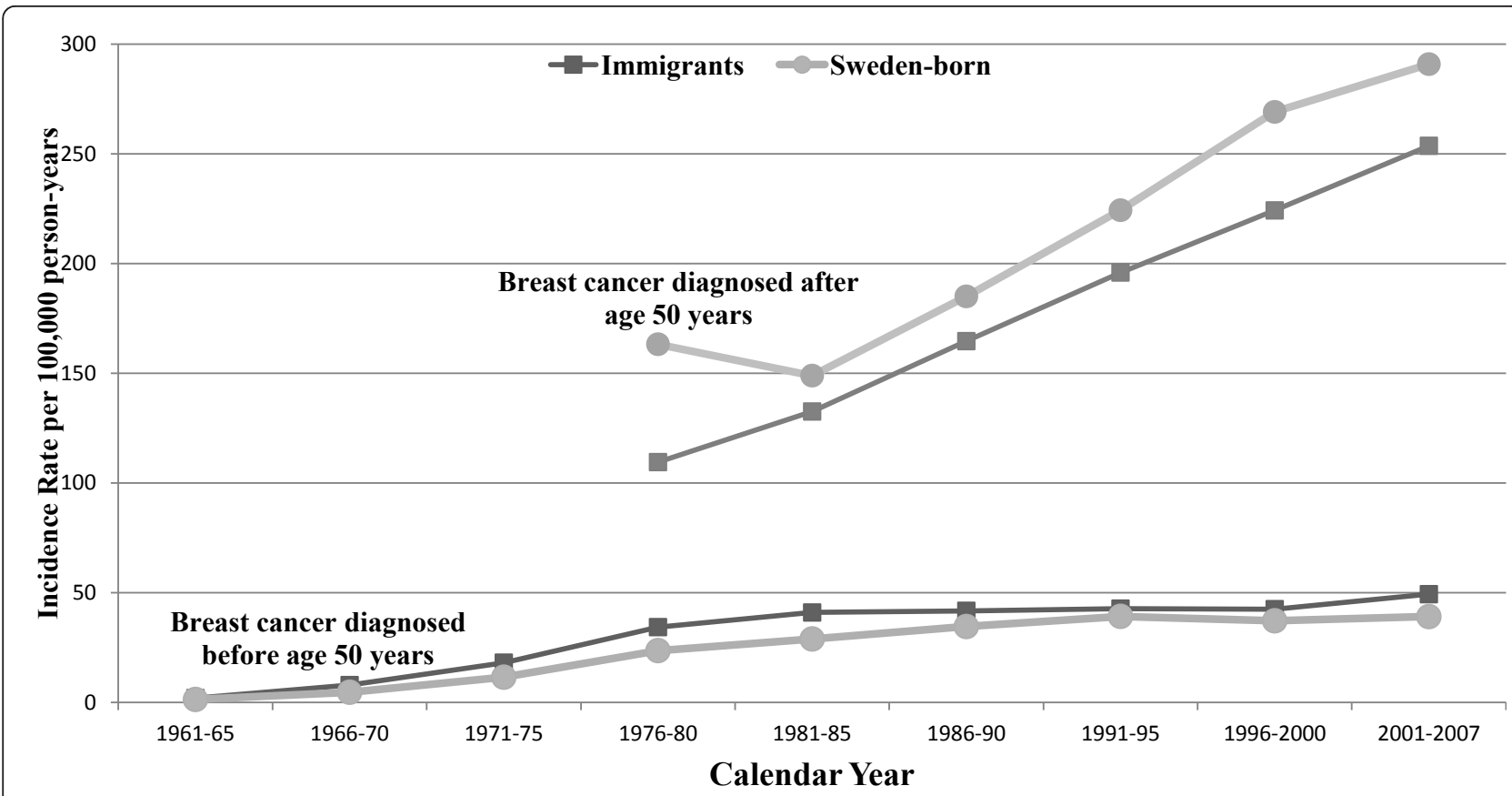

Figure 2- Age-specific incidence rates of breast cancer among immigrants and Sweden-born women by calendar period of follow-up, 1961-2007

Figure 2

When we stratified breast cancer case fatality by country of birth, we found a similar case fatality for most immigrants compared with native Swedes (Table 6). The risk of dying due to breast cancer, however, was 2.5 times higher among immigrants born in Northern Africa $(\mathrm{HR}=2.81,95 \% \mathrm{CI}=1.13$ to 6.96$)$. Analysis of immigrants' daughters at the country level was hampered by lack of power and was, therefore, not included.

When stratifying the results by age at immigration we found an overall similar HR among immigrants who immigrated at ages younger than 35 compared with those who immigrated at older ages (Table 7). However, we found statistically significant risk modification by age at immigration among women from low-risk countries in Africa, Asia and Eastern Europe (data not shown in table). We also found an overall statistically significant higher case fatality among immigrants who stayed less than 30 years compared with those who stayed longer in Sweden (Table 7).

\section{Discussion}

In this large, nation-wide cohort study among women with diagnosis of invasive neoplasm of the breast in Sweden, we found that women with the most education, as an indicator of socio-economic position, had statistically, significantly $20 \%$ to $30 \%$ higher incidence of breast cancer, but $30 \%$ to $40 \%$ better breast cancer survival compared with women with the lowest educational level irrespective of country of birth. Furthermore, our study showed increasing breast cancer incidence over the last decades in native Swedes and immigrants, albeit not in immigrants' daughters. We found immigrant women overall had a lower incidence of breast cancer than native Swedes with the lowest risk, almost half that of native Swedes, observed among women born in China, South Korea, Thailand, Viet Nam, Turkey and Chile

Table 7 Hazard ratio (HR) of breast cancer case fatality by age at immigration and duration of residence.

\begin{tabular}{lcc}
\hline & \multicolumn{2}{c}{ Breast cancer-case fatality } \\
\cline { 2 - 3 } & Death & $\mathbf{H R}^{*}(\mathbf{9 5 \%} \mathbf{C l})$ \\
\hline Age at immigration & & \\
0 to 14 & 716 & $0.73(0.501 .05)$ \\
15 to 34 & 240 & Reference \\
$35+$ & & \\
Duration of residence & 134 & $\mathbf{1 . 1 4}(\mathbf{0 . 7 2}$ to $\mathbf{1 . 8 0})$ \\
0 to 4 & 272 & $\mathbf{1 . 5 2}(\mathbf{1 . 0 8}$ to $\mathbf{2 . 1 3})$ \\
5 to 14 & 363 & $\mathbf{1 . 3 4}(\mathbf{1 . 0 6}$ to $\mathbf{1 . 7 1 )}$ \\
15 to 29 & 275 & Reference \\
$30+$ &
\end{tabular}

* All HRs are adjusted for age at follow-up, calendar period of diagnosis and region of origin. 
There are a number of known risk factors for breast cancer; high socioeconomic status $[15,16]$, radiation exposure [17], diethylstilbestrol exposure during pregnancy [18], low age at menarche and high age at menopause [19], postmenopausal high body mass index [20], and long term use of hormone replacement therapy [21] have been associated with increased risk of breast cancer while low age at first childbirth [19], high parity [19] and physical activity $[15,22,23]$ have been associated with lower risk of breast cancer. In general, about $90 \%$ of the breast cancer cases in high income countries are attributed to hormone level-related factors [24]. The low incidence found in this study among immigrant women, apart from the borderline significant decreased risk among some groups, such as immigrants from Finland and Germany, could partially be attributed to differences in distribution of breast cancer risk factors in comparison to native women. We lacked information on individual risk factors, the clinical stage and histological grade. We should point out that the observed small significant absolute differences between immigrants and Sweden-born women, for example, among immigrants from Finland, might be due to the large number of populations under study.

Our finding of younger age at diagnosis among immigrants' daughters could simply be due to the younger age of the population at risk in this group.

Our finding of the convergence of incidence towards the Swedish incidence level was observed among immigrants' daughters, particularly among those whose parents were from low-risk areas, such as Asia and Latin America. This is in agreement with studies on immigrants from Asia and Latin America in the US and immigrants from Ireland in the UK $[6,25,26]$. A significant variation in incidence by race and ethnicity and strong scientific support has been accumulating for the fact that immigrants undergo changes in breast cancer risk after migration, mostly due to modifiable environmental and behavioral factors [6,27]. The level of acculturation, measured by language use or duration of residence, has been shown to be inversely associated with age at menarche, number of pregnancies and duration of breastfeeding; and has been positively linked to age at first full-term pregnancy, obesity, screening attendance and health care utilization [28-30]. In our study, we examined changes in risk with respect to three indicators of acculturation, that is, age at immigration, duration of residence and generation in Sweden. Previous studies on cancer among immigrants in Sweden neither focused on breast cancer per se nor considered age at immigration and duration of residence [31-34]. Some studies highlighted the importance of exposures, such as diet and residential history. Among adult immigrants from low-risk areas, place of birth acted as a protective factor, while breast cancer incidence was shown to increase among the younger migrants [27]. Our findings of risk modification by age at immigration among women from low-risk countries in Africa, Asia and Eastern Europe and by duration of residence, in line with studies on Italian migrants and US Hispanics, suggest that the timing of migration might be a strong predictor of breast cancer incidence, and highlights the importance of life style factors $[28,35,36]$.

In this study, we found that women with the most education had statistically significantly $30 \%$ to $40 \%$ better breast cancer survival compared with women with the lowest educational level, irrespective of country of birth. Furthermore, our study showed decreasing breast cancer case fatality over the last decades in native Swedes and immigrants but not in immigrants' daughters. We found disparities in breast cancer case fatality by age at diagnosis and calendar period of diagnosis. Immigrants whose cancer was diagnosed after age 50 or in 2001 to 2007 had higher breast cancer case fatality compared with corresponding native Swedes.

Our findings of increasing incidence [37-39] and improving survival [40] over time were similar to the results of previous studies conducted in Sweden. These studies, however, were confined to women living in Sweden without considering their immigrant status. Our findings of disparity in breast cancer case fatality between immigrants and native Swedes are in line with the results of studies in the US [41,42]. The decrease in breast cancer case fatality is probably reflecting the better prognosis and, thus, increasing survival of breast cancer cases [43]. Factors such as advances in therapy and earlier detection through the implementation of screening programs are suggested elements responsible for the better prognosis [44].

The disparities we found between immigrants and native Swedes by age and calendar period of diagnosis are novel. These disparities might be due to lack of absorbance in the screening program among older and recently arrived immigrants. Establishment of mammography screening in Sweden has progressed from a pilot study in 1974 through clinical trials to service screening $[45,46]$. Screening with mammography for early detection of breast cancer has been provided by all Sweden's 26 county councils since 1997 . It took 23 years from the initial pilot study through clinical trials to the establishment of mammography service screening throughout Sweden. Mammography outside screening programs, clinical mammography, is available throughout Sweden. A negative relation between the use of clinical mammography and participation in the screening programs has been noticed [47]. Previous studies in Sweden have found several socio-economic and health behaviorrelated factors that predict non-attendance in 
mammographic service screening programs and found that non-attendees are at higher risk for advanced breast cancer [48-50]. Two other studies have shown that immigrants, especially those from non-Nordic countries, were more than twice as likely to be non-attendees compared with Swedish-born women [51,52]. These results are in agreement with our findings and warrant further attention for adhering migrant population to mammographic screening. We found overall similar case fatality in immigrants, immigrants' daughters and native Swedes. Case fatality increased significantly by increasing age at immigration and decreased significantly by increasing duration of residence. It was also statistically, significantly higher among immigrants if cancer was diagnosed after age 50 or in most recent years.

Inequalities in case fatality within different education groups among both immigrants and Swedes found in this study is in line with the cumulative evidence from different epidemiological studies, including studies from Sweden with equal access to a uniform health care system, indicating higher breast cancer mortality among socio-economically disadvantaged women [53-56].

It has already been shown that breast cancer mortality is lower in Sweden than in Denmark [57]. In contrast, we found a similar mortality among immigrants from Denmark and native Swedes, which supports the conclusion by Jensen and colleagues emphasizing the importance of early breast cancer detection in Sweden on decreasing breast cancer mortality [58]. Our findings of higher breast cancer survival by increasing age is in line with the results of previous Swedish studies implying that young women affected by breast cancer have higher mortality even if diagnosed early and receiving intensive treatment $[59,60]$. In addition, we found higher mortality among immigrant than native women if they were diagnosed at older ages. The older immigrant women in Sweden, thus, suffer from higher mortality for two reasons: first, their old age; since later diagnosis in older women has been associated with worse mortality in Sweden $[59,60]$, and second, their migration status. The differences in management and screening uptake have already been observed among immigrant women compared to natives and might be an explanation for this finding [61-63].

Different pathological stage at diagnosis and biological markers, including estrogen, progesterone and HER2 receptor status, have been indicated as probable factors responsible for disparities found among different ethnic and socio-economic groups in US and Sweden [64-68]. There are studies that have shown significant differences in the frequency of estrogen/progesterone positivity between Vietnamese and Swedish breast cancer patients [69] and between different major racial/ethnic groups in the US [70-72]. We found that some part of these discrepancies in case fatality might be due to different distribution of these factors among the study population. We had no access to individual data on these factors and were not able to consider them in our analysis. A limitation of our study, which applies to almost all migrant studies, is the possibility of selection bias. The population of interest is likely to be non-random and thus may not represent the populations of origin. In addition, forces of selection probably differ from population to population. International immigration is feasible more among women with higher education and socioeconomic position, factors which are known to be associated with the risk of breast cancer. Immigrants from different countries listed in this study vary by reasons for immigration and selection forces. Part of the variations we found among the immigrants could be due to these differences. These limitations need special consideration when comparisons are made among countries of birth and call for studies with focus on each specific group to disentangle the effect of selection forces from environmental factors on breast cancer risk and case fatality.

The major strength of our study is the populationbased design with a long follow-up of all native Swedes and foreign-born women during the study period. Because information on exposure was collected before the diagnosis of cancer, misclassification with regards to exposure is unlikely and, if any, is most likely independent of breast cancer and thus, non-differential.

\section{Conclusions}

In conclusion, our finding of convergence of breast cancer incidence towards the Swedish level among immigrants' daughters plus effect-modification by age at immigration and duration of residence among immigrants indicates the importance of pre-migration factors, and highlights the importance of early-life exposures. Disparities found in cases of fatality among immigrants when stratifying results by age and duration of residence, age at immigration and country of birth emphasize the importance of designing and implementing active interventions in order to reduce incidence and, particularly, fatality in susceptible sub-groups of the female population. In addition, the lower risk of breast cancer among immigrant women outlines the importance of understanding how lifestyle factors in these women differ from those with high risk, so that preventative measures may be implemented.

\section{Abbreviations}

Cl: confidence interval; HR: hazard ratio; ICD-7: International Classification of Disease, Seventh Edition; IRR: incidence rate ratio; LISA: Database for Health Insurance and Labor Market studies; PIN: personal identity number; SEP: socioeconomic position. 


\section{Author details}

${ }^{1}$ Division of Epidemiology, Institute of Environmental Medicine, Karolinska Institutet, Box 210, SE-171 77, Stockholm, Sweden. ${ }^{2}$ Kermanshah University of Medical Sciences, Kermanshah, Iran. ${ }^{3}$ Department of Epidemiology and Biostatistics, Karolinska Institutet, PO Box 281, SE-171 77, Stockholm, Sweden. ${ }^{4}$ Unit of Clinical Epidemiology, Department of Medicine, SOLNA, Karolinska Institutet, SE-171 76, Stockholm, Sweden.

\section{Authors' contributions}

TM and OB had full access to all of the data in the study and take responsibility for the integrity of the data and the accuracy of the data analysis. $\mathrm{OB}$ and TM conceived and designed the study. TM acquired the data. Analysis and interpretation of data were undertaken by $\mathrm{OB}, \mathrm{PH}, \mathrm{AE}$ and TM. OB drafted the manuscript. Critical revision of the manuscript for important intellectual content was conducted by OB, PH, AE and TM. Statistical analysis was conducted by OB. TM obtained funding. All authors read and approved the final manuscript.

\section{Competing interests}

The authors declare that they have no competing interests.

Received: 29 July 2011 Revised: 23 December 2011

Accepted: 6 January 2012 Published: 6 January 2012

\section{References}

1. GLOBOCAN 2002: Cancer Incidence, Mortality and Prevalence Worldwide. [http://www-dep.iarc.fr].

2. Committee on Cancer Control in Low and Middle Income Countries Board on Global Health: The cancer burden in low and middle income countries and how it is measured. In Cancer Control Opportunities in Low and Middle Income Countries. Edited by: Sloan FA, Gelband H. Washington, D.C: The National Academies Press; 2007:

3. Chia KS, Reilly M, Tan CS, Lee J, Pawitan Y, Adami HO, Hall P, Mow B: Profound changes in breast cancer incidence may reflect changes into a Westernized lifestyle: a comparative population-based study in Singapore and Sweden. Int J Cancer 2005, 113:302-306.

4. Parkin DM, Bray F, Ferlay J, Pisani P: Global cancer statistics, 2002. CA Cancer J Clin 2005, 55:74-108.

5. Parkin DM, Khlat M: Studies of cancer in migrants: rationale and methodology. Eur J Cancer 1996, 32A:761-771.

6. Ziegler RG, Hoover RN, Pike MC, Hildesheim A, Nomura AM, West DW, WUWilliams AH, Kolonel LN, Horn-Ross PL, Rosenthal JF, Hyer MB: Migration patterns and breast cancer risk in Asian-American women. J Natl Cancer Inst 1993, 85:1819-1827.

7. Brinton LA, Benichou J, Gammon MD, Brogan DR, Coates R, Schoenberg JB: Ethnicity and variation in breast cancer incidence. Int J Cancer 1997, 73:349-355.

8. Ludvigsson JF, Otterblad-Olausson P, Pettersson BU, Ekbom A: The Swedish personal identity number: possibilities and pitfalls in healthcare and medical research. Eur J Epidemiol 2009, 24:659-667.

9. Barlow L, Westergren K, Holmberg L, Talback M: The completeness of the Swedish Cancer Register: a sample survey for year 1998. Acta Oncol 2009, 48:27-33.

10. Official Statistics of Sweden: Census of the Population and Housing in 1970, part 13: Occupation and Education Stockholm, Sweden: Statistics Sweden; 1975.

11. Longitudinal integration database for health insurance and labour market studies (LISA by Swedish acronym).

12. Statistska Centralbyrån: Bakgrundsfakta till befolknings-ochvälfärdsstatistik (The Multi-Generation Registry) Örebro: Statistska Centralbyrån; 2001.

13. Centre for Epidemiology of the National Board of Health and Welfare: Dodsorsaker 2007 (Causes of death 2007) Stockholm, Sweden: Statistska Centralbyrån; 2009.

14. Johannesson I: The total population register of statistics Sweden. New possibilities and better quality Örebro: Statistics Sweden; 2002.

15. Moradi T, Adami HO, Bergstrom R, Gridley G, Wolk A, Gerhardsson M, Dosemeci M, Nyren O: Occupational physical activity and risk for breast cancer in a nationwide cohort study in Sweden. Cancer Causes Control 1999, 10:423-430.
16. Pukkala E, Weiderpass E: Time trends in socio-economic differences in incidence rates of cancers of the breast and female genital organs (Finland, 1971-1995). Int J Cancer 1999, 81:56-61.

17. Goodman MT, Cologne JB, Moriwaki H, Vaeth M, Mabuchi K: Risk factors for primary breast cancer in Japan: 8-year follow-up of atomic bomb survivors. Prev Med 1997, 26:144-153.

18. Sanderson M, Williams MA, Daling JR, Holt VL, Malone KE, Self SG, Moore DE: Maternal factors and breast cancer risk among young women. Paediatr Perinat Epidemiol 1998, 12:397-407.

19. Kelsey JL, Gammon MD, John EM: Reproductive factors and breast cancer. Epidemiol Rev 1993, 15:36-47.

20. Renehan AG, Tyson M, Egger M, Heller RF, Zwahlen M: Body-mass index and incidence of cancer: a systematic review and meta-analysis of prospective observational studies. Lancet 2008, 371:569-578.

21. Breast cancer and hormone replacement therapy: collaborative reanalysis of data from 51 epidemiological studies of 52,705 women with breast cancer and 108,411 women without breast cancer. Collaborative Group on Hormonal Factors in Breast Cancer. Lancet 1997, 350:1047-1059, Erratum in: Lancet 1997, 350:1484.

22. Moradi T, Adami HO, Ekbom A, Wedren S, Terry P, Floderus B, Lichtenstein P: Physical activity and risk for breast cancer a prospective cohort study among Swedish twins. Int J Cancer 2002, 100:76-81.

23. Moradi T, Nyren O, Zack M, Magnusson C, Persson I, Adami HO: Breast cancer risk and lifetime leisure-time and occupational physical activity (Sweden). Cancer Causes Control 2000, 11:523-531.

24. McPherson K, Steel CM, Dixon JM: ABC of breast diseases. Breast cancerepidemiology, risk factors, and genetics. BMJ 2000, 321:624-628.

25. Stanford JL, Herrinton LJ, Schwartz SM, Weiss NS: Breast cancer incidence in Asian migrants to the United States and their descendants. Epidemiology 1995, 6:181-183.

26. Menck HR, Henderson BE, Pike MC, Mack T, Martin SP, SooHoo J: Cancer incidence in the Mexican-American. J Natl Cancer Inst 1975, 55:531-536.

27. Andreeva VA, Unger JB, Pentz MA: Breast cancer among immigrants: a systematic review and new research directions. J Immigr Minor Health 2007, 9:307-322.

28. John EM, Phipps Al, Davis A, Koo J: Migration history, acculturation, and breast cancer risk in Hispanic women. Cancer Epidemiol Biomarkers Prev 2005, 14:2905-2913.

29. Brown WM, Consedine NS, Magai C: Time spent in the United States and breast cancer screening behaviors among ethnically diverse immigrant women: evidence for acculturation? J Immigr Minor Health 2006, 8:347-358

30. Cairney J, Ostbye T: Time since immigration and excess body weight. Can J Public Health 1999, 90:120-124.

31. Hemminki K, Li X: Cancer risks in Nordic immigrants and their offspring in Sweden. Eur J Cancer 2002, 38:2428-2434.

32. Hemminki $\mathrm{K}$, Li $\mathrm{X}$, Czene $\mathrm{K}$ : Cancer risks in first-generation immigrants to Sweden. Int J Cancer 2002, 99:218-228.

33. Mousavi SM, Brandt A, Weires M, Ji J, Sundquist J, Hemminki K: Cancer incidence among Iranian immigrants in Sweden and Iranian residents compared to the native Swedish population. Eur J Cancer 2010, 46:599-605.

34. Nilsson B, Gustavson-Kadaka E, Rotstein S, Hakulinen T, Rahu M, Aareleid T: Cancer incidence in Estonian migrants to Sweden. Int J Cancer 1993, 55:190-195.

35. Coates MS, Kaldor JM, Hayes D: Cancer in Italian migrant populations. New South Wales, Australia. IARC Sci Publ 1993, 138-148.

36. Bouchardy C, Mirra AP: Cancer in Italian migrant populations. Sao Paulo, Brazil. IARC Sci Publ 1993, 103-116.

37. Garne JP, Aspegren K, Balldin G, Ranstam J: Increasing incidence of and declining mortality from breast carcinoma. Trends in Malmo, Sweden, 1961-1992. Cancer 1997, 79:69-74.

38. Persson I, Bergstrom R, Sparen P, Thorn M, Adami HO: Trends in breast cancer incidence in Sweden 1958-1988 by time period and birth cohort. Br J Cancer 1993, 68:1247-1253.

39. Rutqvist LE: Increasing incidence and constant mortality rates of breast cancer: time trends in Stockholm County 1961-1973. Breast Cancer Res Treat 1984, 4:233-243.

40. Foukakis T, Fornander T, Lekberg T, Hellborg H, Adolfsson J, Bergh J: Agespecific trends of survival in metastatic breast cancer: 26 years 
longitudinal data from a population-based cancer registry in Stockholm, Sweden. Breast Cancer Res Treat 2011, 130:553-560.

41. Chuang SC, Chen W, Hashibe M, Li G, Zhang ZF: Survival rates of invasive breast cancer among ethnic Chinese women born in East Asia and the United States. Asian Pac J Cancer Prev 2006, 7:221-226.

42. Gomez SL, Clarke CA, Shema SJ, Chang ET, Keegan TH, Glaser SL: Disparities in breast cancer survival among Asian women by ethnicity and immigrant status: a population-based study. Am J Public Health 2010, 100:861-869.

43. Berrino F, De Angelis R, Sant M, Rosso S, Bielska-Lasota M, Coebergh JW, Santaquilani M: Survival for eight major cancers and all cancers combined for European adults diagnosed in 1995-99: results of the EUROCARE-4 study. Lancet Oncol 2007, 8:773-783.

44. Keegan TH, Quach T, Shema S, Glaser SL, Gomez SL: The influence of nativity and neighborhoods on breast cancer stage at diagnosis and survival among California Hispanic women. BMC Cancer 2010, 10:603.

45. Lundgren B, Jakobsson S: Single view mammography: a simple and efficent approach to breast cancer screening. Cancer 1976, 38:1124-1129.

46. Tabar L, Fagerberg CJ, Gad A, Baldetorp L, Holmberg LH, Grontoft O, Ljungquist $\mathrm{U}$, Lundstrom $\mathrm{B}$, Manson JC, Eklund $\mathrm{G}$, et al: Reduction in mortality from breast cancer after mass screening with mammography. Randomised trial from the Breast Cancer Screening Working Group of the Swedish National Board of Health and Welfare. Lancet 1985, 1:829-832.

47. Olsson S, Andersson I, Karlberg I, Bjurstam N, Frodis E, Hakansson S: Implementation of service screening with mammography in Sweden: from pilot study to nationwide programme. J Med Screen 2000, 7:14-18.

48. Lagerlund M, Sparen P, Thurfjell E, Ekbom A, Lambe M: Predictors of nonattendance in a population-based mammography screening programme; socio-demographic factors and aspects of health behaviour. Eur J Cancer Prev 2000, 9:25-33.

49. Lagerlund M, Widmark C, Lambe M, Tishelman C: Rationales for attending or not attending mammography screening-a focus group study among women in Sweden. Eur J Cancer Prev 2001, 10:429-442.

50. Zackrisson S, Andersson I, Manjer J, Janzon L: Non-attendance in breast cancer screening is associated with unfavourable socio-economic circumstances and advanced carcinoma. Int J Cancer 2004, 108:754-760.

51. Lagerlund M, Maxwell AE, Bastani R, Thurfell E, Ekbom A, Lambe M: Sociodemographic predictors of non-attendance at invitational mammography screening-a population-based register study (Sweden). Cancer Causes Control 2002, 13:73-82.

52. Zackrisson S, Lindstrom M, Moghaddassi M, Andersson I, Janzon L: Social predictors of non-attendance in an urban mammographic screening programme: a multilevel analysis. Scand J Public Health 2007, 35:548-554.

53. Lagerlund M, Bellocco R, Karlsson P, Tejler G, Lambe M: Socio-economic factors and breast cancer survival-a population-based cohort study (Sweden). Cancer Causes Control 2005, 16:419-430.

54. Downing A, Prakash K, Gilthorpe MS, Mikeljevic JS, Forman D: Socioeconomic background in relation to stage at diagnosis, treatment and survival in women with breast cancer. Br J Cancer 2007, 96:836-840.

55. Kogevinas $M$, Porta $M$ : Socioeconomic differences in cancer survival: a review of the evidence. IARC Sci Publ 1997, 177-206.

56. Rutqvist $L E$, Bern A: Socioeconomic gradients in clinical stage at presentation and survival among breast cancer patients in the Stockholm area 1977-1997. Int J Cancer 2006, 119:1433-1439.

57. Tulinius H, Storm HH, Pukkala E, Andersen A, Ericsson J: Cancer in the Nordic countries, 1981-86. A joint publication of the five Nordic Cancer Registries. APMIS Supp/ 1992, 31:1-194.

58. Jensen AR, Garne JP, Storm HH, Engholm G, Moller T, Overgaard J: Does stage at diagnosis explain the difference in survival after breast cancer in Denmark and Sweden? Acta Oncol 2004, 43:719-726.

59. Eaker S, Dickman PW, Bergkvist L, Holmberg L, Uppsala/Orebro Breast Cancer Group: Differences in management of older women influence breast cancer survival: results from a population-based database in Sweden. PLOS Med 2006, 3:e25

60. Fredholm H, Eaker S, Frisell J, Holmberg L, Fredriksson I, Lindman H: Breast cancer in young women: poor survival despite intensive treatment. PLOS One 2009, 4:e7695.

61. Vermeer B, Van den Muijsenbergh ME: The attendance of migrant women at the national breast cancer screening in the Netherlands 1997-2008. Eur J Cancer Prev 2010, 19:195-198.
62. Coughlin SS, Wilson KM: Breast and cervical cancer screening among migrant and seasonal farmworkers: a review. Cancer Detect Prev 2002, 26:203-209.

63. Islam N, Kwon SC, Senie R, Kathuria N: Breast and cervical cancer screening among South Asian women in New York City. J Immigr Minor Health 2006, 8:211-221.

64. Baquet CR, Mishra Sl, Commiskey P, Ellison GL, DeShields M: Breast cancer epidemiology in blacks and whites: disparities in incidence, mortality, survival rates and histology. J Natl Med Assoc 2008, 100:480-488.

65. Ooi SL, Martinez ME, Li Cl: Disparities in breast cancer characteristics and outcomes by race/ethnicity. Breast Cancer Res Treat 2011, 127:729-738.

66. Chlebowski RT, Chen Z, Anderson GL, Rohan T, Aragaki A, Lane D, Dolan NC, Paskett ED, McTiernan A, Hubbell FA, Adams-Campbell LL, Prentice R: Ethnicity and breast cancer: factors influencing differences in incidence and outcome. J Natl Cancer Inst 2005, 97:439-448.

67. Telli ML, Chang ET, Kurian AW, Keegan TH, McClure LA, Lichtensztajn D, Ford JM, Gomez SL: Asian ethnicity and breast cancer subtypes: a study from the California Cancer Registry. Breast Cancer Res Treat 2011, 127:471-478

68. Eaker S, Halmin M, Bellocco R, Bergkvist L, Ahlgren J, Holmberg L, Lambe M, Uppsala/Orebro Breast Cancer G: Social differences in breast cancer survival in relation to patient management within a National Health Care System (Sweden). Int J Cancer 2009, 124:180-187.

69. Thang VH, Tani E, Johansson H, Adolfsson J, Krawiec K, Van TT, Skoog L: Difference in hormone receptor content in breast cancers from Vietnamese and Swedish women. Acta Oncol 2011, 50:353-359.

70. Chu KC, Anderson WF: Rates for breast cancer characteristics by estrogen and progesterone receptor status in the major racial/ethnic groups. Breast Cancer Res Treat 2002, 74:199-211.

71. Li Cl, Malone KE, Daling JR: Differences in breast cancer hormone receptor status and histology by race and ethnicity among women 50 years of age and older. Cancer Epidemiol Biomarkers Prev 2002, 11:601-607.

72. Cunningham JE, Montero AJ, Garrett-Mayer E, Berkel HJ, Ely B: Racial differences in the incidence of breast cancer subtypes defined by combined histologic grade and hormone receptor status. Cancer Causes Control 2010, 21:399-409.

\section{doi:10.1186/bcr3086}

Cite this article as: Beiki et al: Breast cancer incidence and case fatality among 4.7 million women in relation to social and ethnic background: a population-based cohort study. Breast Cancer Research 2012 14:R5.

\section{Submit your next manuscript to BioMed Central and take full advantage of:}

- Convenient online submission

- Thorough peer review

- No space constraints or color figure charges

- Immediate publication on acceptance

- Inclusion in PubMed, CAS, Scopus and Google Scholar

- Research which is freely available for redistribution

Submit your manuscript at www.biomedcentral.com/submit
C Biomed Central 